Accepted for publication by the Curriculum Journal

\title{
Learner agency and the curriculum: a critical realist perspective
}

\begin{abstract}
Agency, understood as the capacity to act independently and to make one's own choices, is considered central to children's development. Thus, education, and hence education curricula, have a role in the development of learner agency. While curriculum development is a key focus for educational theory, research, policy, and classroom practice, the potential implications of curriculum content selections for learner agency remain underexplored. Theoretically this paper engages with critical realism, explaining how it can provide theoretical foundation for a more comprehensive view of learner agency and, by implication, more balanced curricula. Empirically, the paper draws on the findings from a content analysis of the national curriculum documents of four countries with relatively high scores in international comparative tables, England, Australia, Hong-Kong, and Canada, to develop a new typology of primary curricula. Based on the extent of emphasis placed on knowledge versus skills, values, and attitudes, three types of curricula were identified: knowledge-based, skills-oriented, and learner-centred. Due to its significant theoretical and practical influence globally, we focus on the knowledge-based model and its likely impact on students' agency. We conclude by highlighting the importance of making learner agency a key orientation of the curriculum and suggesting directions for future research.
\end{abstract}

Keywords: curriculum, learner agency, knowledge, critical realism 
Accepted for publication by the Curriculum Journal

\section{Introduction}

The past decade has witnessed a vigorous debate on the school curriculum with questions concerning curriculum design and implementation moving to the top of the educational research and policy agenda internationally. Academic and policy discussions about curriculum design are mostly skewed towards exploring various aspects of structure and the demands imposed by them on the curriculum content, focussing primarily on the question of what it is that children need to be taught in order to be able to respond effectively to the social, political, and economic challenges of the 21 st-century world. In spite of the longstanding philosophies of child-centred teaching, appearing for example in the works of John Dewey, Lev Vygotsky, Jean Piaget, and Rudolf Steiner, and the policy focus on students as agents in reports such as England's Plowden Report of 1967, understanding learner agency and how it is influenced by the various aspects of educational context have been neither sufficiently theoretically nuanced nor empirically informed.

In recent years, there have been signs that educational theory and research have begun to place considerations of agency on a more consistent and rigorous basis. For example, substantial work has been done in the areas of pupil voice and children's rights including some increase in attention given to acknowledging the rights of children in the policies and practices of schooling (DCSF, 2008, DfE, 2014). Significant contributions to the area of pupil voice include The International Handbook of Student Experience in Elementary and Secondary Schools (Thiessen and Cook-Sather, 2007), a series of reports commissioned by the Cambridge Primary Review (Robinson, 2014; Robinson and Fielding, 2007, 2010), and other studies (Hargreaves, 2017; Hopkins, 2008; Leitch and Gardner, 2013). This research raises issues concerning students' sense of control and power over the learning process and its implications for achievement and enjoyment of learning in schools. It reveals the centrality of agency to learner identity, learner autonomy, and learner behaviour (Gao, 2010; Toohey \& Norton, 2003; Ushioda, 2007) and highlights "the importance of empowering learners to lead their own learning” (Robinson, 2014, p. 18). It has also been shown that students improve academically when given the power to co-construct curriculum and instruction alongside their teachers (Rudduck \& Flutter, 2000). Increasing learner agency, that is giving students voice and choice in how they learn, creates more meaningful school experiences for students thus helping to meet their fundamental developmental needs (Mitra, 2004). This work renders the question of agency highly relevant to a range of educational issues, including curriculum design and delivery. 
In spite of global curriculum visions increasingly focussed not merely on what it is that ideal graduates must know or be able to do, but also on what the citizens of the future should be like (see the UNESCO 2014 Report and the UN post-2015 Education and Development Framework), debates about curriculum orientations rarely incorporate questions of learner agency. What children are taught in schools and what kind of meanings the curriculum gives or denies access to affects not only students' intellectual development, but also their view of themselves, their place in the world, and their ability to influence their learning and life chances. It is therefore essential to consider the potential impacts of curriculum content on students' sense and exercise of agency in the classroom, with the ensuing implications for children's immediate and long-term educational outcomes.

The paper begins by examining the concept of agency, drawing on prior research to provide a picture of learner agency, its essential components, and the key factors affecting its development and manifestations. We contribute to understanding of learner agency by using critical realism to provide a sound theoretical foundation for the view of learner agency as a multi-dimensional, dynamic, and contextualised entity. This represents an important step towards developing a comprehensive and nuanced theoretical framework for decisions about curriculum content - a long-needed element in curriculum development, as noted by Moore and Young (2001). This first section of the paper sets the context for the arguments concerning the relationship between curriculum content and learner agency that we subsequently develop and that constitute the main contribution of the paper.

The arguments made in the paper are also informed by the empirical findings from our study on the place of knowledge in the primary curricula of four different countries, commissioned as part of the proposed redevelopment of the Primary School Curriculum in Ireland by the National Council for Curriculum and Assessment (NCCA). A content analysis of the curriculum texts informed reflections on the potential implications of different curriculum designs for learner agency. In this paper, we report those aspects of the analysis which bring into focus the apparent assumptions made by the curriculum texts about learner agency within the primary classroom and consider their potential impact on student development and learning behaviour. The paper concludes by outlining the importance of the curriculum typology and offers some related directions for future investigations - theoretical and empirical - into the relationship between curriculum content and learner agency.

\section{Learner agency: a critical realist view}


Agency is commonly defined as individuals' will and capacity to act (Gao, 2010). In social theory, the concept of agency figures prominently in the debates about the relationship between structure (social contexts) and agency (individual persons), where opinions are polarised as to whether agential intentions and actions play the key role in shaping the social order or themselves are determined by the objective contexts in which agents are placed. From a critical realist perspective, both accounts are flawed. As Archer (2007) explains, the socio-centric approach commits the fallacy of 'downward conflation', for it assumes the total primacy of structure over agency whilst neglecting the capacity of agents to make sense of and respond to structural influences. The agency-centred perspective, on the other hand, falls into the trap of 'upward conflation', since it treats agency as the key single force that shapes the reality whilst reducing the entire social order to a mere aggregate of agential actions and consequences thereof. Some social theorists, such as Giddens (1994) and Bourdieu (1984), have attempted to transcend the dichotomy between structure and agency by refusing to distinguish one from the other - instead, they conceive of structure and agency as coconstitutive and inseparable in their manifestation. As Archer indicates (2007), this leads directly to the trap of 'central conflation', where one is not allowed to draw a distinction between the properties and effects of structure and those of agents and, therefore, left with no means of exploring how and with what implications, either for individuals or society, the two elements interact with each other. In critical realism, the way out of the above theoretical and analytical impasses is found in the conception of social reality as consisting of two distinct but constantly interacting strata, structure and agency, both of which are accorded causal efficacy, i.e. the capacity to exert causal effects on the surrounding world.

The question of the relationship between structure and agency acquires new prominence against the backdrop of attempts to understand the key factors affecting the learning process. Here too, deep divisions run between those who give primacy to learning environments - physical settings and socio-cultural contexts in which learning takes places and those who assign individuals' cognition a dominant role in the unfolding of learning (Mercer, 2011). As has already been said, critical realism renders the dispute between structure and agency to solely define the look of reality as superfluous, for it locates the source of all personal and social outcomes in the relationship of reciprocal causality between the two elements. Likewise, in education, social contexts and individual students act as interacting determinants of learning environments, processes, and outcomes. In support of this claim, a study by Gao (2010) indicates that contexts and agency both contribute to pupils' selection and use of second language learning strategies. Research in the area of 
language learning has produced a body of evidence further highlighting the role of agency in influencing students' learning behaviours. In a paper examining learner agency in the context of language acquisition, Mercer (2011) cites a number of studies suggesting that having a sense of agency and being able to exercise this agency to actively shape the learning experience constitute essential pre-requisites for effective self-learning. Bown (2009, p. 580) finds a direct link between agency and students' capacity for autonomous learning, concluding that: 'to effectively manage learning and regulate emotional responses, learners must be aware of their own agency and must believe themselves capable of exercising that agency'.

The sense of agency and the exercise of agency are two distinct, albeit closely interrelated, aspects of the agentic system. Being aware of oneself as an active agent does not always result in the actual exercise of that agency, as Mercer (2011) insightfully points out. This claim has far-reaching implications in understanding the impact of curriculum content on students' agency. It suggests that merely instilling in children a sense of agency is not sufficient for empowering them to take ownership of their learning. Real opportunities are required for pupils to exercise their agency in relation to various aspects of the learning process thereby acquiring effective control over it. Furthermore, such opportunities need to be made explicit and readily accessible, so that every student can easily recognise and tap into their latent potential for learning. Following Mercer (2011), we use the term 'affordances' to describe opportunities for learning that are available within particular contexts, and that are recognised by students. The concept of affordances aligns perfectly with critical realism, for it finely captures the mutual causality of structure and agency. According to a critical realist account of reality, the enabling or constraining effects of structure can manifest themselves only in relation to agential intentions and actions, for 'constraints require something to constrain, and enablements something to enable' (Archer, 2003 , p. 4). Just as structural properties remain neutral until agents contemplate or embark on a certain endeavour, which structure can either facilitate or inhibit, so do contextual opportunities become affordances only when students recognise the potential for learning inherent in them. This gives rise to an important consideration, namely that agential capacity is determined not only by contextual factors, but also an individual's psychological cognitive, emotional, motivational - states and abilities, highlighting the relevance of the intrapersonal dimension of agency. This explicit recognition of learners' perceptions and belief systems as a key element of agency speaks directly to another fundamental tenet of critical realism, namely the conferring of ontological status on the unobservable yet real 
entities that profoundly affect agential intentions and actions, such as emotions, attitudes, and beliefs. By distinguishing structure from agency, critical realism allows us to recognise that children's concerns, aspirations, and interests are not simply part of the social context, but constitute inherent elements of students' subjectivities, which are being constantly moulded and shaped by the structural properties of learning environments.

Critical realist theory adds an extra layer of depth to the argument about the importance of contextual affordances for promoting students' agency. According to critical realism, structural constraints and enablements may influence the intentions and actions of agents through mere anticipation: the perceived conduciveness of surrounding contexts to a particular achievement is likely to strengthen an individual's intention to pursue her endeavour, while an expectation of failure may discourage her from embarking on it (Archer, 2003). This claim is acutely pertinent to educational contexts, where structures within which learning takes places often act as powerful barriers for pupils to fulfil their potential. Research goes a long way to reveal the relationship between the structural properties of educational systems and learners' self-esteem and perceived agentic capacity. Reay and Wiliam (1999) provided insight into the link between children's perceptions of national curriculum assessments and their self-image. The potential of the test results to profoundly affect students' view of themselves, both as learners as well as individuals, was finely captured in the following quote from a Year 6 pupil: 'I'm frightened I'll do the SATs and I'll be a nothing' (Reay and Wiliam, 1999, p. 345). This argument is developed further in Reay's (2017) most recent book highlighting the unhealthy state of guilt and anxiety experienced by children who are put in low ability groups and its impact on learning outcomes.

If students are faced with a predetermined and rigidly fixed curriculum with no room for creativity, innovation, and change, they can hardly develop positive perceptions of their ability to influence the direction of their learning and are therefore likely to refrain from attempting to become active, creative, self-guided learners. This conjecture is supported by empirical research which shows how believing that learning development is within their control contributes to students' personal sense of agency (Mercer, 2011, 2012). In a study focussing on a tertiary-level language learner, Mercer (2011) demonstrates how beliefs about contextual factors, from socio-cultural to familial to immediate classroom settings, affect students' willingness to exhibit agency in schools. More specifically, the extent to which certain contexts are imposed on students or created or chosen by them has considerable implications for learners' agentic systems. Drawing on these insights, Mercer (2011, p. 435) conceptualises agency as 'latent potential' to engage in self-directed learning whose 
realisation depends on a student's sense of agency and the actual and perceived opportunities to exercise this agency in a given context. This definition satisfies the critical realist principle necessitating acknowledgment of the role of both structure and agency in shaping individual and collective processes and their outcomes. From a critical realist perspective, then, agency is best defined not simply in terms of an individual's will and capacity to act, but as 'the socio-culturally mediated capacity to act' (Ahearn, 2001, p. 112, italics added), with an equal emphasis on the contextually situated nature of agency and its potential to actively interact with and influence the surrounding contexts. Learner agency, therefore, has two distinct but equally important dimensions: 1) learners' personal sense of agency, i.e. a belief in their ability to make a difference to their learning within given settings, and 2) learners' agentic behaviour - the point at which students actually exercise their agency by playing an active role in directing the learning process, e.g. making decisions, assuming control, taking an action or refraining from one.

The discussion above highlights that learner agency is situated both contextually, including wider socio-cultural and immediate educational and physical settings, and intrapersonally, that is in terms of individuals' personal beliefs, motivations, attitudes, as well as their actual abilities, capacities, experiences, and past achievements. These represent two of the four levels of contextualisation of agency; in addition, learners' agentic systems are also contextualised on the interpersonal and temporal levels. Interpersonally, learner agency is situated in relation to a range of interactional partners, such as teachers, peers, and parents, all of whom have the potential to profoundly impact the development and manifestations of agency in students. Research demonstrates how teachers can affect learners' sense of personal agency through their behaviour and attitudes towards particular students and the general ambiance they create in the classroom (Mercer, 2011). Temporally, individuals' sense of agency and beliefs about their own agentic capacities are on the one hand grounded on past experiences, while on the other hand serve to inform their future agentic self-image and, consequently, their expectations and goals. The embeddedness of agency in the temporal context adds to the complex dynamism of agency, which does not simply change linearly over time, but constantly fluctuates in response to ongoing changes in other contextual planes within which it is set.

Recognising that agency is contextually, interpersonally, intra-personally, and temporally situated is a crucial step in considering the potential implications of different national curriculum types for learner agency. The extent to which curriculum developers and their curricula take into account the four levels that provide contexts for learner agency may 
Accepted for publication by the Curriculum Journal

have far-reaching consequences for students' actual and perceived capacity to exercise agency in the classroom and take ownership of their learning.

\section{An empirically informed typology of primary curricula}

Critical realism, in relation to student agency, was used as part of the theoretical framing of the development of a typology of national curriculum models. An empirical study of the place of knowledge in the primary curricula from four jurisdictions, Australia, Canada (Ontario), Hong Kong, and England was undertaken (a formal report produced for the NCCA provides a detailed overview of the study methodology, conclusions, and recommendations: Wyse \& Manyukhina, 2018). The main research questions for this study were:

1. Is knowledge being foregrounded/backgrounded in primary curricula?

2. What is the balance between the acquisition of knowledge and the development of skills/competencies /dispositions?

3. To what extent does knowledge form the framework by which the curriculum is articulated/structured/presented?

4. What are the implications of this analysis for curriculum design, development, and implementation?

The research design was a content analysis combined with elements of critical discourse analysis (description and critical interpretation of a text concerned with identifying how the text is implicated in relations of power - see Fairclough, 2003), focussing on the nature, type, and positioning of knowledge vis-à-vis other curriculum elements.

In order to be comparable with the Irish primary national curriculum of 1999 (which was to be developed as a result of the work reported in this paper and the work of many other experts and stakeholders) the criteria used to make a selection of countries for comparison included the following:

- English language dominant, including national curriculum texts available digitally in English;

- Jurisdictions that have significant levels of ethnic diversity 
- High scoring in PISA outcomes, both in terms of academic performance and equity issues (OECD, 2018)

The following documents were used as the data for the content and discourse analyses:

Australia (AC): The Australian Curriculum: Learning Areas; The Australian Curriculum: General Capabilities; The Australian Curriculum: Cross-Curriculum Priorities.

Canada (Ontario) (OC): The Ontario curriculum subject guides.

Hong-Kong (BECG): The Basic Education Curriculum Guide.

England (NCE): The National Curriculum in England: Framework Document.

There were significant differences between the key texts of the four countries' national curricula in terms of appearance, structure, and length. For example, multiple texts outlining the primary curriculum in Hong Kong, Canada, and Australia in contrast with just one main text in England. To ensure that our analysis was both rigorous and manageable, in each of the four cases we focussed on those curriculum documents and sections of them that had the most significant representations of the role and status of knowledge in the curriculum. The curriculum texts were subjected to a keyword search for mentions of the terms "knowledge" and "know", as dictated by the aims of the original study designed to analyse the place and role of knowledge in primary curricula. Entire sentences in which these terms appeared were extracted and added to an Excel database for analysis, which had four main foci based on frequencies of occurrence. or what we called 'mentions': the types of statements in which knowledge appeared (these included statements outlining curriculum intent, practitioner guidance, learning outcomes; statements describing learning contexts, processes, and experiences); the type of knowledge referred to (disciplinary or non-disciplinary); the implied value of knowledge (intrinsic or instrumental); and the positioning of mentions of knowledge in relation to other curriculum elements, such as understanding, skills, competencies, values, and attitudes.

As a result of the analysis, we proposed a typology that distinguishes three types of curricula based on their specifications about what children should be taught in schools, and to some extent how that should be the main learning activity and outcome intended by the curriculum: 1) knowledge-based, in which the acquisition of disciplinary knowledge represents the main learning activity and outcome intended by the curriculum; 2) skills- 
oriented, which extends the focus of learning to include other curriculum elements, such as competencies and skills, whilst maintaining the emphasis on an in-depth study of subject content from various disciplines; and 3) learner-centred, which prioritizes domainindependent over disciplinary learning with a view to ensuring holistic development of students.

We first provide a general overview of the most important characteristics of the skillsoriented and learner-centred types of curriculum, before offering a detailed analysis of a knowledge-based curriculum and its implications for learner agency. We focus specifically on the knowledge-based model since this model has had significant theoretical and practical influence globally, and because it may potentially have negative effects on students' sense and exercise of agency in the classroom.

An important caveat needs to be offered before we can proceed further. The focus on knowledge was dictated by the aims of the original study; we appreciate that this constitutes only one of many possible prisms through which curriculum content can be examined, including in relation to learner agency. Nonetheless, our analysis brought into light the pertinence of curriculum content orientations to the potential development and manifestations of agency in pupils. The insights we have collected may constitute an essential building block in understanding the potential effects of school curricula on learner agency. While the focus on the study on knowledge, and four examples of primary curricula, does not permit us to claim that our proposed typology is fully comprehensive or final, it extends empirically existing classifications of educational curricula, in particular Ross' (2000) demarcation between content-driven curriculum with a focus on knowing what, objectives-driven curriculum with a focus on knowing how, and process-driven curriculum concerned with the learning process itself. In a similar manner, Doll (1974) divided all curricula into the following three types: those designed around subjects, disciplines, or broad fields; those designed around students; and those designed around social problems. Further distinction is made between traditionalist and progressivist curricula; in this regard, knowledge-based curricula map well onto the traditionalist framework which sees disciplinary knowledge as the most important content that should be taught to all students without differentiation, while skills-oriented and learner-centred curricula are progressivist in their orientation towards skills/values/attitudes and appreciation of students' individuality, accommodated within a flexible learning process. Our analysis of different curriculum content orientations and their implications for learner agency engages with and links planned and hidden curricula (Kelly, 1999): we consider how what is laid down in the syllabus is imbued with assumptions about 
learning and the role of students in it. The idea of null curriculum (Eisner, 1994), which refers to that what is not taught to students, whether intentionally or unintentionally, becomes prominent in our discussion of the absence of learner agency-related concerns and provisions from the knowledge-based curriculum model.

\section{Skills-oriented curriculum model}

In our analysis, the skills-oriented curriculum model is exemplified by the Australian Curriculum (AC) and the Ontario Curriculum (OC). These curricula use traditional subject areas as a basis for the selection and organisation of curriculum content, suggesting that knowledge continues to play a dominant role in the curriculum design framework. At the same time, they exhibit a clear intention to expand the focus of learning beyond disciplinary knowledge to also include subject-specific and general competencies, skills, and understanding. Thus, the AC has a three-dimensional design intended to achieve integration of the following elements:

- disciplinary literacy, defined in terms of confluence of subject-specific knowledge, understanding, and skills

- General Capabilities considered essential and relevant to all learning areas

- Cross-Curriculum Priorities focussed on helping young Australians to become good citizens of the state and responsible members of a global community

Similarly, Ontario's curriculum documentation includes 'Creating Pathways to Success: An Education and Career/Life Planning Program for Ontario Schools' (Ontario Ministry of Education, 2013) and 'Growing Success: Assessment, Evaluation, and Reporting in Ontario Schools' (Ontario Ministry of Education, 2010) documents, which extend the focus of school education beyond acquisition of disciplinary knowledge and skills to include generic, domain-independent learning skills and work habits, namely 'responsibility, organization, independent work, collaboration, initiative, self-regulation' (Ontario Ministry of Education, 2016, p. 26). The AC's and the OC's reduced emphasis on knowledge as the single most important curriculum element was further evidenced by a low number of statements focussing solely on knowledge. The vast majority of knowledge mentions (75\%) featuring in the AC were 'set', i.e. those that place knowledge alongside other curriculum elements, mainly understanding and skills. The following quote provides an example of such mentions: 
The curriculum focuses on the knowledge, understanding and skills necessary to design for effective sustainability action taking into account issues such as resource depletion and climate change (AC: Cross-curriculum Priorities - Sustainability)

Likewise, knowledge is rarely mentioned on its own in the OC subject guides. The documents contain a disproportionately low number of exclusive references to knowledge ( $\sim 16 \%$ compared to $\sim 84 \%$ 'set' mentions) and display a strong tendency to place knowledge alongside other curriculum elements, primarily skills. However, this reduced emphasis on knowledge is not evidence of a shift towards what Young (2007) refers to as "genericism", i.e. prioritisation of domain-independent over subject-specific learning. Both the AC and the OC emphasise disciplinary as opposed to generic understanding and skills. Thus, rather than aiming at raising the profile of cross-disciplinary and soft skills (e.g. cooperation, teamwork), the OC subject guides place emphasis on academic skills considered essential for students' ability to achieve subject-specific learning outcomes, as evidenced by the following quote:

The Native Language curriculum emphasizes the basic knowledge and skills that students must develop in order to write clearly and correctly (OC: Native Languages, p.16)

The importance of disciplinary content in the $\mathrm{AC}$ becomes apparent on reviewing individual programmes of study for the learning areas which are characterised by a high level of specification of the subject-specific knowledge and skills that should be taught to pupils based on their year level. For example, by the end of year 4 , students are expected to:

Understand how to use knowledge of letter patterns including double letters, spelling generalisations, morphemic families, common prefixes and suffixes and origins to spell more complex words (AC: English - Curriculum F-10)

Thus, despite a clear tendency to move away from knowledge as the single most important curriculum element, skills-oriented curricula continue to have disciplinary learning, of which acquisition of subject-specific knowledge and skills is a key focus, as their overarching learning activity and objective. This constitutes the major distinction between skills-oriented and learner-centred curricula, which demonstrate recognition of the need to help pupils to develop not only intellectually, but also personally and socially. While skills- 
oriented curricula are clearly positioned as more than just providers of disciplinary knowledge, as evidenced by the explicit recognition of the importance of understanding and skills, the development of students' identity and belief systems remains largely outside of their scope. For instance, while the inclusion of General Capabilities and Cross-curriculum Priorities into the AC backs up the intention to enable and promote not only intellectual, but also general development of students, both components achieve very little in terms of putting the cultivation of values, dispositions, and attitudes on a par with academic learning. Across all Learning Areas, General Capabilities, and Cross-curriculum Priorities guides we found only ten statements mentioning attitudes/dispositions alongside knowledge; for values, the relevant number of mentions was only five. It is this lack of attention to values and attitudes underpinning personal and social development of students that sets skills-oriented curricula apart from the learner-centred model, characterised by an explicit concern with what is increasingly referred to as "identity education" (see Schachter \& Rich, 2011 for an overview of the concept).

\section{Learner-centred curriculum model}

We identified a learner-centred curriculum as a distinct curriculum type based on our analysis of Hong-Kong's curriculum specified in the Basic Education Curriculum Guide (BECG). The key feature of the learner-centred curriculum model that distinguishes it from the knowledge-based and skills-oriented types is a clearly stated intent to move away from a main focus on knowledge acquisition and towards broader educational goals, such as those of whole-person development and life-long learning. Thus, the BECG explicitly instructs practitioners to 'avoid developing a curriculum that is biased towards knowledge learning' (BECG, Ch.1.5.2, p.8). That holistic student development represents a key educational outcome intended by the curriculum is evident from the statement outlining the main aims of education in the $21^{\text {st }}$ century:

The school curriculum should provide all students with essential life-long learning experiences for whole-person development in the domains of ethics, intellect, physical development, social skills and aesthetics, according to their individual potential, so that all students can become active, responsible and contributing members of society, the nation and the world (BECG, Ch.1.3, p.2) 
The fact that the document contains considerably fewer exclusive knowledge mentions (54 as opposed to 88 'set' mentions) offers further support to the conclusion about the curriculum's shift away from knowledge as the axis around which all learning and assessment is built. There is a clear tendency in the document to place knowledge alongside other curricular elements considered essential for a balanced development of an individual, namely skills, values, and attitudes as can be seen in the following quote:

In addition to acquiring knowledge in class, students are expected to develop learning to learn capabilities as well as positive values and attitudes for achieving the educational aims of whole-person development and life-long learning (BECG, Preamble, p.1)

In continuation of the above recommendations, the document instructs schools to develop assessment strategies that engage the entire spectrum of curricular elements as opposed to testing knowledge alone:

Assessment should not be confined to knowledge. Students' skills, values and attitudes should also be assessed (BECG, Ch.3.5.3, p.10)

This is indicative of the BECG's intention to detract from the status of knowledge as the most important dimension of the curriculum and emphasise the essential role of skills, values, and attitudes in supporting students' development. Indeed, the document is emphatic that 'knowledge, skills, values and attitudes should be of equal importance' (BECG, Ch.1.5.2, p.8) and that schools should design curriculum experiences and outcomes around these three components as opposed to using subjects as the basis for structuring the curriculum. Moreover, unlike skills-oriented curricula, BECG foregrounds generic as opposed to disciplinary skills and capacities, as the following quote illustrates:

(1) (...) increased efforts should be made to develop students' generic skills, values and attitudes to help students achieve a balanced development (BECG, Ch.1.5.2, p.8)

The Hong Kong curriculum particularly encourages approaches to teaching that foster capacity and commitment for independent life-long learning in students: 
Accepted for publication by the Curriculum Journal

Investigation activities not only help students increase their knowledge and enhance their learning capabilities, but also arouse their curiosity, increase their intrinsic motivation for learning, and above all, nurture a positive attitude towards learning (BECG, Ch.3C, p.1)

Students' individuality and the need to ensure that learning activities resonate with pupils' personal interests, ambitions, and goals is evident in the curriculum specification. Another important feature of the learner-centred curriculum instantiated by the BECG is that it encourages teachers to act as enablers and activators of learning as opposed to mere deliverers of content. Increased emphasis is placed on enabling students to take a conscious initiative and responsibility in learning, an instruction that speaks directly to concerns about developing learner agency:

While teachers' guidance is important during the learning process, opportunities and space should be provided for students to explore and co-construct knowledge with peers to encourage them to actively participate in developing independent and selfdirected learning skills (BECG, Ch.1.5.2, p.8)

Strong focus on generic as opposed to disciplinary knowledge and skills, consistent emphasis on values and attitudes as equally important educational outcomes, and encouragement of pedagogical approaches that are conducive to achieving the aims of wholeperson development and life-long learning are the key features distinguishing the learnercentred curriculum model from the knowledge-based and skills-oriented types. In this regard, a learner-centred curriculum comes closest to embodying the idea of a personally relevant school curriculum, one that is founded on a recognition of the important implications of curriculum content descriptions for learner experiences and that gives students opportunities to develop and exercise agency in in their learning.

\section{Knowledge-based curriculum}

In our analysis, the type of curriculum which we refer to as knowledge-based was represented by the National Curriculum in England (NCE). The important role of disciplinary knowledge in the NCE is apparent through the use of traditionally defined subject areas (English, Mathematics, Science, Art and Design, Computing, Design and Technology, 
Geography, History, Languages, Music, and Physical Education) as a basis for the selection and organisation of curriculum content. That disciplinary knowledge plays a key role in the framing of the NCE becomes further evident through the positioning of knowledge in statements outlining overall curriculum intent, as in quotes 1 and 2:

(1) The national curriculum provides pupils with an introduction to the essential knowledge that they need to be educated citizens (NCE, p.6)

(2) The national curriculum provides an outline of core knowledge around which teachers can develop exciting and stimulating lessons to promote the development of pupils' knowledge, understanding and skills as part of the wider school curriculum (NCE, p.6)

The fact that knowledge is first in a list of learning outcomes to be promoted by teachers, and that it is considered essential for the development of students as 'educated citizens', strongly indicates the NCE's intention to accord high priority to knowledge acquisition. Overall, the NCE is articulated in terms of educational goals that are both premised on as well as geared towards acquisition of knowledge (quote 2) and testable outcomes specified at the level of particular subjects and learning stages (quote 3 and 4).

(3) By the end of year 2, pupils should know the number bonds to 20 and be precise in using and understanding place value (NCE, p.101)

(4) Pupils should be taught about: a study of an aspect or theme in British history that extends pupils' chronological knowledge beyond 1066 (NCE, p.191).

The above quotes also serve to demonstrate that the NCE is characterised by a high level of specification of disciplinary knowledge that should be taught to students at different stages. A high level of prescriptiveness in relation to the subject content makes explicit the prioritisation of disciplinary knowledge in the curriculum. It is telling that out of all knowledge mentions found in the NCE a disproportionate $91 \%$ refer to disciplinary knowledge. Quote 5 and 6 reveal the only two mentions we classified as non-disciplinary knowledge in the NCE: 
(5) Good comprehension draws from linguistic knowledge (in particular of vocabulary and grammar) and on knowledge of the world (NCE, p.14)

(6) All pupils must be encouraged to read widely across both fiction and non-fiction to develop their knowledge of themselves and the world in which they live (...) (NCE, p.14)

The fact that an overwhelming majority of references to knowledge in the NCE explicitly refer to disciplinary knowledge indicates an intention to establish a strong relation between academic knowledge and the content of the curriculum. Quotes 7 and 8 support this conclusion:

(7) Pupils should be taught to: read aloud books closely matched to their improving phonic knowledge, sounding out unfamiliar words accurately, automatically and without undue hesitation (NCE, p. 27)

(8) Pupils should be taught to use knowledge of solids, liquids and gases to decide how mixtures might be separated, including through filtering, sieving and evaporating (NCE, p.169)

There is a clear tendency in the NCE to prioritise knowledge over other curriculum elements, as evidenced by a high number of exclusive knowledge mentions in the document $(\sim 65 \%)$. A relatively small number $(\sim 35 \%)$ of statements containing references to knowledge among a set of other curriculum elements suggests that the NCE does not intend to put skills, values, and attitudes on a par with knowledge in the curriculum development framework. However, it might be argued that skills feature in the NCE in less explicit ways. If we accept the view that high-level knowledge is essentially the skill of being able to differentiate between different concepts (Gill \& Thomson, 2012), the following statement (quote 9) might be seen as intending to include skills in the specification of educational goals:

(9) The national curriculum for mathematics aims to ensure that all pupils: (...) develop conceptual understanding and the ability to recall and apply knowledge rapidly and accurately (NCE, p.99) 
The emphasis on encouraging the development of deep conceptual understanding in students might also be indicative of the NCE's intention to promote an active form of pedagogy which prioritises reflexive engagement with knowledge over routinized acquisition of scientific concepts and facts (Young, 2007). It is nonetheless quite clear that generic skills, values, and attitudes are emphasised very little in the NCE. The word 'values' appears in the entire document only five times, and three of the five mentions refer to value as a numerical concept. Similarly, there are only three references to attitudes in the whole of the NCE, and all three refer to attitudes towards learning activities (quote 10) rather than ways of thinking and feeling about important life-world issues, thereby reinforcing the curriculum's narrow focus on the development of students' disciplinary-based knowledge.

(10) Pupils should be taught to: develop positive attitudes towards and stamina for writing (...) (NCE, p.31)

A very low emphasis on generic skills and near absence of references to values and attitudes in the NCE suggest a lack of intention to position the curriculum more widely as a driver of children's personal and social growth.

As the example of the NCE makes clear, a knowledge-based curriculum is characterised by a strong emphasis on disciplinary knowledge: its key rationale for the inclusion of content in programmes of study is that it represents selected bodies of knowledge from various academic disciplines which students are expected to master. Where such a curriculum is in place, acquisition of academic knowledge becomes the key purpose of education, while the shaping of identities and the development of values and attributes in students as part of the curriculum is minimised. Knowledge-based curricula are therefore focussed firmly on what students should know as opposed to how they should be. The underlying idea of a knowledge-based curriculum is that of providing students with access to knowledge rather than putting students at the centre of the learning process. Such curricula are not grounded in terms of learner-centred or social-interests-centred orientations; instead, students' entitlement to knowledge becomes a key rationale behind the curriculum design and implementation.

What, then, might the implications of the knowledge-based curriculum model be for learner agency? One risk is the failure of a knowledge-based curriculum to pay heed to learners' agentic systems that begins with a failure to acknowledge a connection between curriculum and pedagogy. Thus, within the NCE knowledge features strongly in statements 
of practitioner guidance ( $\sim 69 \%)$, statements of learning outcomes $(\sim 22 \%)$, and statements of intent $(\sim 10 \%)$, knowledge mentions are absent in statements describing learning contexts and process. This can be explained in the following ways: 1) the word knowledge simply does not appear in statements of learning process and contexts in the NCE; 2) the document contains very few, if any, such statements. Both these explanations suggest that the NCE does not aim to establish a strong connection between curriculum content and learning process and contexts, implying a low emphasis on the centrality of the learner. If oblivious to the implications of curriculum content for teaching and learning, knowledge-based curricula underplay the fundamental dimension of learner agency, namely the actual and perceived ability of students to engage in agentic behaviour within the confines of the classroom.

Further, knowledge-based curricula are typically disconnected from the four levels at which learner agency is contextualised. At an interpersonal level, knowledge-based curriculum frameworks appear to assign teachers the role of knowledge transmitters as opposed to facilitators or mediators of the learning process. A high level of specification and linear sequencing of the subject content as a curriculum principle can impede teachers and students from becoming co-participants in the process of discovering, exploring, and creating knowledge. The status and power dynamic that ensues from a situation where teachers assume positions of authority and dominance in relation to students can prevent learners from developing a sense of autonomy and empowerment relative to their learning. At an interpersonal level, a curriculum whose key rationale for content selection is that it reflects traditional disciplinary knowledge is unlikely to leave room to build teaching on learners' individual characteristics, such as their personal backgrounds, interests, goals, and priorities. Such curricula are also unlikely to give rise to learning experiences that have personal relevance for students and hence lack the potential to facilitate and enhance learners' agentic systems. Since a knowledge-based curriculum takes almost no account of students' experiences - past, present, or future - it is also unable to align with the temporal dynamics of their unfolding life histories, leaving students' learning unconnected to the temporal context in which their agency is embedded. Finally, at a contextual level, a firmly fixed curriculum composed of rigidly structured bodies of knowledge whose delivery follows a linear sequence of hierarchically predefined steps provides minimal opportunities for students to be active participants in their learning.

\section{Discussion and conclusions}


In this paper we have examined two important educational issues, learner agency and curriculum text content. Although these two issues have been the foci of significant strands of research they have rarely been brought into dialogue with each other. With regard to learner agency, we have drawn on prior research, mostly in the area of language learning, to demonstrate the multidimensional, dynamic, and variedly situated nature of agency and the role of both individual - students' personal perceptions and belief systems - and contextual socio-cultural, educational, and familial settings - factors in shaping learners' agentic systems. Having emphasised the importance of approaching learner agency from a perspective that is able to account for both agentic and structural influences on learning behaviour, we have proceeded to examine whether and to what extent different curriculum content orientations lean themselves to or align with learner agency-centred considerations and interests.

In this final part of the paper, we offer some suggestions concerning the development of curricula in the future. Curriculum planning has to start by providing an answer to a broader question: what is the fundamental purpose of education, and how should this be related to curriculum design? A curriculum that relies on the epistemic authority of traditional academic knowledge as its main rationale can fail to address purposes and their relationship with curriculum, and hence fail to be grounded in a socially relevant account of aims. In his most recent critique of 'powerful knowledge', White (2018, p. 333) points out precisely this limitation of a subject-based curriculum, claiming that 'the starting-point for thought about what an educational curriculum should be must lie within ethics, not epistemology'. Perhaps the starting points for curriculum design should lie with both.

If an ethical stance towards decisions about curriculum is adopted, it becomes evident that the pursuit of knowledge is not sufficient to account for national curricula that should reflect democratically developed societal aims for its young people. Educational depth and specialism are pre-requisites for success in modern economies, characterised by progressive growth in the division of intellectual labour and the increasing dominance of knowledgedriven sectors, and modern curricula should therefore be effective in preparing learners to become experts in one area or another Beck (2013, p. 188). Yet, the question of curriculum design cannot be resolved through disciplinary bases alone. Firstly, as Yates and Millar (2016) note, neither specific content selections, nor pedagogical approaches and practices, nor the trajectory of students' intellectual development can be deduced from the disciplines themselves. Secondly, the benign nature of empowerment through knowledge should not itself be taken for granted. Certain forms of knowledge may empower individuals or groups 
to act in ways that are not at all good or desirable (Beck, 2013). An educationally and theoretically defensible curriculum model therefore needs to rely on a wider set of criteria, in order to ensure that only benign forms of empowerment are promoted by schools. If 'ethics is rightly where justifications of curricula begin' (White, 2018, p. 332), then curriculum policy decisions should necessarily be considered with a close reference to one of the most fundamental educational challenges of today. The tension between the demands to satisfy the knowledge and skills requirements of the $21^{\text {st }}$ century economy and overcome inequality in education is a major source of confusion in contemporary curriculum policy and implementation (Moore and Young, 2001). One possible solution to some of these tensions is the design of curricula that combine social usefulness with personal relevance, that is a curriculum that provides access to the knowledge, values, and skills that are essential for success in the 21 st century society and workplaces in a way that is relatable, accessible, and meaningful to all learners. Thus, the curriculum of the future should have two fundamental dimensions, social and individual, i.e. it must be effective in creating generations capable of effective action for a better society while bearing direct relevance to the personal experiences, interests, and aspirations of students. This sentiment is shared by some sociologists of education, such as Beck (2013, p. 187), who insists on the relevance of personal and social identity in providing a foundation for the curriculum:

Equipping young people to understand themselves, both as individuals and as members of complex, rapidly changing societies, is, or should be, one of the most important of educational aims, and logically should be so for all future citizens in democratic countries.

The need to position curriculum more widely as a driver of personal and social development of students is also recognised at the international level: the UN post-2015 Education and Development Framework identifies preparing children for life-long learning and citizenly engagement as the central purpose of education in the 21st century, while the 2014 UNESCO Report states that schools should support learners in developing not only cognitive skills, but also socio-emotional and behavioural skills, such as the ability to act effectively and responsibly in local, national, and global contexts (UNESCO GMR, 2014, p. 295). This implies that the key orientation of the school curriculum should be to enhance children's capacity to utilise their agentic resources, both with respect to their own life courses and within a society. A focus on agency is crucial not only for personal empowerment and enhancement of students, 
but also for the wider social, political, and economic purposes. For example, the ability to effectively respond to climate change, world poverty, human rights violations and other global challenges requires a strong sense of agency and belief in one's own capacity to exercise that agency to good effect (the student school 'strikes' of early 2019 were an example of what can happen if agency is denied). Given the many contradictions involved in achieving simultaneously economically prosperous, socially just, and environmentally sustainable living environment, such as the tension between economic growth and environmental protection, it is critical to support young generations in developing the capacity to think critically and independently, engage in autonomous decision-making based on informed choice, and act effectively in a manner that ensures the essential balance between individual and societal interests and priorities.

A comprehensively informed curriculum needs to be underpinned by a theory that acknowledges the mutual causality of structure and agency and its implications for learning behaviour and educational outcomes. In this paper, we have shown how a critical realist framework can inform a more refined understanding of learner agency, its key influencing factors, and its multi-level contextual sensitivity. From this point of view, critical realism has strong - and so far under-utilised - potential to guide the development of a sound theoretical base for a holistic/learner-centred curriculum. Critical realism's acknowledgment of the mutually affecting interaction between individuals and their contexts provides foundation for a broad and balanced curriculum framework - that which reflects the centrality of the social progress imperative to decisions about what an ideal graduate should know and be able to do, while also ensuring personal relevance, manifested in the ability of students to draw meaningful connections between what they learn and their subjective experiences, interests, and backgrounds. The key strengths of critical realist philosophy as far as curriculum thinking is concerned is that it recognises the ontological reality and epistemic significance of subjective experiences and considers them with reference to objective contexts, thus enabling understanding of the drivers, patterns, and influencing factors of agentic behaviour in educational settings. This responds directly to Mercer's call for an approach that treats learners 'as holistic beings nested within the bigger systems of their personal histories and the entirety of their lives and multiple contexts' (2011, p. 435).

Further research will need to add more theoretical and empirical detail to the picture emerging from the discussion developed in this paper. On a theoretical level, we need to understand how individual agency intertwine with collective agency in learning contexts and what demands this relationship may impose on curriculum design and implementation. While 
this paper has focussed specifically on children's agency, student learning is shaped by many different sets of agents, both those who have a direct, unmediated presence in classrooms, such as teachers, and those who remain outside the immediate learning environment of a school yet profoundly influence learning outcomes and experiences, such as parents, teacher educators, policy makers, and educational researchers. Our analysis did not closely consider which curriculum type offers most space for the teachers to make decisions with implications for learner agency, although we do note the BECG's encouragement of teachers' role as enablers and activators of learning and the view of teachers as transmitters of knowledge implied by the NC. It is quite likely that teacher agency is treated by learner-centred and knowledge-based curricula in the same way learner agency is, that is largely neglected by the former and arguably catered for by the latter. However, it is yet to be established whether leaving the responsibility and freedom to teachers to make their own choices of teaching approaches and methods will offer more or less room for learner agency.

Thus, the key empirical question to address is what actually happens in classrooms and schools. There is a need to investigate how students actually experience different types of curricula and what consequences for their agency these experiences produce. Research on the ground is essential for improving curriculum theory and practice, for it is not sufficient to simply identify the assumptions underlying curriculum or merely change its content. The multidimensionality of agency and its contextualisation at multiple levels - intrapersonal, interpersonal, contextual, and temporal - mean that there is no simple measure that can ensure the development of agency in students so the curriculum needs to attend to a range of components constituting learners' agentic systems. This is likely to involve both shaping students' beliefs and perceptions about themselves and their surrounding contexts in a way that encourages agentic behaviour as well as providing real opportunities for students to use their agentic resources and effectively manage their learning experiences. It is also important to recognise that motivation and capacity for agentic behaviour will vary both inter- and intra-personally among students instead of just assuming that every student is necessarily driven to reach his or her maximum agentic potential (Mercer, 2012). It is therefore necessary to directly explore both the contextual factors affecting expressions of learner agency in the classroom and students' views and perceptions regarding their desired and actual agentic standpoint. The question of agency needs to be placed within a comprehensive sociological and philosophical framework, one that can offer a multi-focus lens capable of capturing both individual and social influences bearing upon agency. 
Accepted for publication by the Curriculum Journal

Given the importance of agency in enabling students to become autonomous, selfguided learners, providing deeper theoretical and empirical insights into learner agency is a crucial step in developing the curriculum of the future. Which particular curriculum decisions, including content selections, will be most effective in providing children with epistemic access essential for becoming independent agents is a question that needs to be high on the educational research agenda internationally.

\section{References}

Ahearn, L. M. (2001). Language and agency. Annual Review of Anthropology, 30, 109-137.

Archer, M. (2003). Structure, Agency, and the Internal Conversation. Cambridge, UK: Cambridge University Press.

Archer, M. S. (2007). Making our way through the world: Human reflexivity and social mobility. Cambridge, UK: Cambridge University Press.

Australian Curriculum, Assessment and Reporting Authority [ACARA]. (2014). Foundation to year 10 curriculum. Retrieved fhttps://www.australiancurriculum.edu.au/f-10-curriculum

Australian Curriculum, Assessment and Reporting Authority [ACARA]. (2012). The Australian Curriculum: Cross-curriculum Priorities - Sustainability. Retrieved from: https://www.australiancurriculum.edu.au/f-10-curriculum/cross-curriculum-priorities/sustainability/

Beck, J. (2013). Powerful knowledge, esoteric knowledge, curriculum knowledge. Cambridge Journal of Education, 43(2), 177-193.

Bourdieu, P. (1984). Distinction. Cambridge, MA: Harvard University Press.

Bown, J. (2009). Self-regulatory strategies and agency in self-instructed language learning: A situated view. The Modern Language Journal, 93(4), 570-583.

Curriculum Development Council. (2014). Basic education curriculum guide - To sustain, deepen and focus on learning to learn (Primary $1-6$ ). Retrieved from http://www.edb.gov.hk/attachment/en/curriculum-development/doc-reports/guide-basic-educurriculum/BECG_2014_en.pdf

Department for Education. (2013). The National Curriculum in England: Key Stages 1 and 2 framework document. Retrieved from:

https://www.gov.uk/government/uploads/system/uploads/attachment_data/file/425601/PRIM ARY_national_curriculum.pdf 
Accepted for publication by the Curriculum Journal

Doll, R. C. (1996). Curriculum improvement: Decision-making and process (9th ed.). Boston: Allyn \& Bacon.

Eisner, E. W. (1994). The educational imagination: On the design and evaluation of school programs. New York: MacMillan College Publishing Company.

Fairclough, N. (2003). Analysing discourse: Textual analysis for social research. London: Routledge.

Gao, X. (2010). Strategic language learning: The roles of agency and context. Multilingual Matters.

Giddens, A. (1994). Living in a post-traditional society. In Beck, U., Giddens, A., \& Lash, S. (Eds.), Reflexive Modernization (pp. 56-109). Cambridge, UK: Polity Press.

Gill, S. \& Thomson, G. (2012). Rethinking secondary education: A human-centred approach. Harlow: Pearson.

Kelly, A. V. (2009). The curriculum: Theory and practice. London: Sage.

Mercer, S. (2011). Understanding learner agency as a complex dynamic system. System, 39(4), 427-436.

Mercer, S. (2012). The complexity of learner agency. Apples-Journal of Applied Language Studies, 6(2), 41-59.

Moore, R. (2013). Social realism and the problem of the problem of knowledge in the sociology of education. British Journal of Sociology of Education, 34(3), 333-353.

Moore, R., \& Young, M. (2001). Knowledge and the curriculum in the sociology of education: towards a reconceptualisation. British Journal of Sociology of Education, 22(4), 445-461.

OECD. (2018). Programme for International Student Assessment (PISA) data.

Retrieved from http://www.oecd.org/pisa/data/

Ontario Ministry of Education. (2001). The Ontario curriculum grades 1-8: Native Languages [Program of Studies]. Retrieved from http://www.edu.gov.on.ca/eng/curriculum/elementary/nativelang18curr.pdf

Ontario Ministry of Education. (2010). Growing Success: Assessment, Evaluation, and Reporting in Ontario Schools. Toronto, ON: Queen's Printer.

Ontario Ministry of Education. (2013). Creating Pathways to Success: An Education and Career/Life Planning Program for Ontario Schools. Toronto, ON: Queen's Printer.

Plowden (1967). Children and their Primary Schools. Report of the Central Advisory Council for Education (England). London: HMSO. 
Accepted for publication by the Curriculum Journal

Reay, D. (2017). Miseducation: Inequality, education and the working classes. Policy Press.

Reay, D. \& Wiliam, D. (1999). 'I'll be a nothing': structure, agency and the construction of identity through assessment. British Educational Research Journal, 25(3), 343-354.

Reiss, M.J. \& White, J. (2013). An Aims-Based Curriculum: The significance of human flourishing for schools. London: Institute of Education Press.

Ross, A. (2000) Curriculum: Construction and technique. London: Falmer Press.

Schachter, E. P. \& Rich. Y. (2011). Identity Education: A new conceptual framework for researchers and practitioners. Educational Psychologist, 46(4), 222-238.

Toohey, K. \& Norton, B. (2003). Learner autonomy as agency in sociocultural settings. In: Palfreyman, D., Smith, R.C. (Eds.), Learner Autonomy Across Cultures. Palgrave Macmillan, Basingstoke, pp. 58-72.

UNDES (2015). Transforming our world: the 2030 Agenda for Sustainable Development, New York: UN Department of Economics and Social Affairs.

UNESCO-GMR (2014). Education for All: Global Monitoring Report 2014. Paris: UNESCO.

Ushioda, E. (2007). Motivation, autonomy and sociocultural theory. In: Benson, P. (Ed.), Learner Autonomy 8: Teacher and Learner Perspectives. Authentik, Dublin, pp. 5-24.

White, J. (2018). The weakness of 'powerful knowledge'. London Review of Education, 16(2), 325-335.

Wyse, D. and Manyukhina, Y. (2018). Research informed analysis on the place of knowledge in a redeveloped primary curriculum: Final Report. Prepared for the National Council for Curriculum \& Assessment Ireland. Retrieved from https://www.ncca.ie/media/3502/seminar_two_wyse_paper.pdf

Yates, L. \& Millar, V. (2016). 'Powerful knowledge' curriculum theories and the case of physics. The Curriculum Journal, 27(3), 298-312.

Young, M. (2007). Bringing Knowledge Back In: From social constructivism to social realism in the sociology of education. London: Routledge. 